\title{
HEALTH CARE PROVIDERS' KNOWLEDGE AND PRACTICE OF FOCUSED ANTENATAL CARE IN A COTTAGE HOSPITAL IN ENUGU STATE, SOUTH EAST NIGERIA
}

\author{
IDANG N. OJONG, EUNICE NWONU \& MARGARET INEMESIT AKPAN
}

(Received 1 July 2016; Revision Accepted 21 August 2016)

\begin{abstract}
The potential of antenatal care for reducing maternal morbidity and mortality and improving newborn survival and health is widely acknowledged. The study sought to investigate Health Care Providers knowledge and practice of focused antenatal care in a cottage Hospital Okpatu. Qualitative ethnographical research design was adopted, while in-depth interview guide and observational checklist were the instruments for data collection. Findings revealed poor knowledge of concept, components, timing of visits on focused antenatal care and non compliance with the guidelines for the practice of focused antenatal care, because of health workers lack of knowledge on focused antenatal care. Conclusively, effort to improve antenatal care should address shortage of trained staff through expanding training opportunities. Based on the above, intensive awareness and retraining of health workers and monitoring and supervision of health care providers on evidence based focused antenatal care is recommended for health care providers in the study area. There is need for health care providers to motivate local government authority in the area to supply more equipment to ensure adequacy of resources to deliver quality care. Also, there should be strategies for implementation of existing policy concerning Focused antenatal care in the study area.
\end{abstract}

KEYWORDS: Focused Antenatal Care, Knowledge, Practice.

\section{INTRODUCTION}

Antenatal care (ANC) coverage is a success story in Africa, since over two thirds of pregnant women $(69 \%)$ have atleast one ANC contact. However, to achieve the full life- saving potential that ANC promises for women and babies, four visits providing essential evidence based interventions, a package often called focused Antenatal care (FANC) is required (World Health Organization, 2010). Antenatal services comprise of complete health supervision of the pregnant women in order to maintain, protect and promote health and wellbeing of the mother and the fetus (Dustan,2010).

Adesokan (2011), describes antenatal care services as the attention, education, supervision and treatment given to the pregnant women from the time conception is confirmed until the beginning of labour, in order to ensure safe pregnancy, labour and puerperium. Qualitative antenatal services are care given to pregnant women by a skilled or trained health care provider to promote the health and survival of mother and child (Reproline, 2015). The FANC services refer to minimum number of four antenatal clinic visits, each of which has specific items of client assessment, education and care to ensure early detection and prompt management of complications (Gaba, 2011). Focused antenatal care which is evidence based, client centred goal directed care, provided by skilled health care provider with emphasis on quality rather than frequency of visits is an approach to be adopted globally. The approach accepts the view that every pregnant woman is at risk of complication and that all women should therefore receive the same basic care and monitoring for complication (World Health Organization 2005).

WHO (2007) ANC randomized trial manual describes the basic component of the new WHO ANC model. It provides detailed instructions on how to conduct the four- visits schedule of the basic component of the new WHO model. The focused ante natal care differs from traditional ante natal care because it emphasis evidence based quality rather than quantity of visits and this care is rendered by skilled care provider. It includes a classifying form for easy assessment of a woman's eligibility for the basic component and provides a checklist of activities that are performed throughout the four- visits schedule. It is important to emphasize that the basic component of the new WHO ANC model is intended only for the management of pregnant women

Idang Neji Ojong, Department of Nursing Science, University of Calabar, Calabar, Cross River State, Nigeria. Eunice Nwonu, Department of Nursing Sciences, University of Nigeria, Enugu Campus, Enugu State, Nigeria. Margaret Inemesit Akpan, Department of Nursing Science, University of Calabar, Calabar, Cross River State, Nigeria. 
who do not have evidence of pregnancy - related complications, medical conditions or major healthrelated risk factors. For the management of women who have such conditions, health providers are advised to follow the recommended established procedures of their clinic or hospital.

The clinics or hospitals that do not have established procedures for women with pregnancy related complications or that wish to update the ones they currently have can use the WHO Reproductive Health Library to identify evidence- based interventions. The WHO manual on FANC allows periodic update to include any pertinent scientific evidence that becomes available (Akpanah 2011).

FANC aims to promote the health of mothers and their babies through:

- Targeted assessment of pregnant women to facilitate identification and treatment of disease, early detection of complication and other potential problems that can affect outcome of pregnancy and delivery

- Prophylaxis and treatment for anemia, malaria and sexually transmitted infections including HIV/ AIDS, urinary tract infection and tetanus.

- Prophylaxis refers to an invention aimed at preventing a disease or disorder from occurring. FANC also aims to give holistic individualized care to each woman to help maintain the normal progress of her pregnancy through timely guidance and advice on:

- $\quad$ Birth preparedness

- Nutrition, immunization, personal hygiene and family planning.

- Counseling on danger symptoms that indicate pregnant woman should get immediate help from a health professional.

According to Jones (2010) focused antenatal care which is an amiable development is also meant to promote maternal and new born health and survival through:

(a) Early detection and treatment of problems and complications

(b) Prevention of complications and diseases.

(c) Birth preparedness and complications readiness; and

(d) Health promotion

The promotion of FANC is one of the strategies aimed at reducing the high rate of maternal and prenatal mortality among African women and their infants. This approach also helps by reaching women at the threshold of safe motherhood.

Globally, FANC was designed and committed to achieving millennium development goals MDG5 to improve maternal health with a target of reducing the maternal mortality rate by three quarters over the period 1990 - 2015, but this was not achieved. Intensive awareness campaign has been conducted in the state to improve health workers knowledge of and practice of FANC and the women access to the services and this yielded no result.

Despite the fact that efforts have been made globally and nationally to promote the knowledge and practice of FANC, health care providers in the study area seem not to avail themselves of this opportunity. This is what prompted the study.

\section{Statement of Problem}

Every local government in Enugu State has atleast two health care centres with their complement of health care providers. The health care providers have received training on provision of FANC services and are expected to apply the knowledge to their practice. It has been 2 years since the last training and there has not been any documented study on their knowledge and practice of FANC, although a number of such studies have been documented in south west region of Nigeria. The researcher wonders what the situation is in Enugu realizing that poor knowledge and non implementation of FANC will lead to non detection and improper management of early signs of complications that might result in maternal and neonatal morbidity and mortality. This concern gave the researcher the impetus to undertake the study.

\section{Purpose}

The purpose of the study was to assess Health care providers' knowledge and practice of focused antenatal care in a cottage hospital in Enugu Sate, South East Nigeria.

\section{Significance of the study}

The findings from the study will reveal areas of gap in knowledge and practice of FANC. This will assist program planner to know areas to emphasis during future training of health care providers on FANC services. If this is properly addressed, health care providers will implement FANC and the complications that arise from poor implementation which if eliminated will have a positive impact on maternal and child morbidity and mortality.

\section{LITERATURE REVIEW}

\section{Knowledge of focused antenatal care}

Experiences from different countries have shown that reducing maternal mortality may depend in part on the availability and use of professional health care providers during labour and delivery and a referral mechanism for obstetric care for managing complications, or use of basic essential obstetric care facilities for all delivery (Etuk, Itam \& Asuquo 2009). Ojong, Uga and Chiotu, (2015) in a cross sectional descriptive study on Knowledge and Attitude of women towards Focused Antenatal Care in the south -East Nigeria found out that $42 \%$ of the respondents had good knowledge on timing of visit, 52\% respondents identified ignorance as a factor affecting FANC services implementation, $66 \%$ accepted that FANC is not enforced by their care facility as a result of policy concerning the practice of FANC, only $6 \%$ of the respondents disagree that early detection of diseases are a major component of FANC. All the respondents $100 \%$, were unaware of the component of FANC.

Also findings from, the study by Karin (2014) on focused Antenatal care in practice in kilomero valley, Tanzania showed that: $62 \%$ of health care providers had poor knowledge of timing of visit in FANC, guidelines 
were not frequently adhered to, and diagnostic examinations were not carried out by health care providers. Consultation times were short (12 minutes for first visit) and health problems may thus be missed.

\section{Practice of focused antenatal care}

In practice of FANC, Ekabua, Ekabua and Njoku, (2011) in their study to assess health workers knowledge and practice of FANC in Nigeria used five teaching hospitals, the result showed that the knowledge of component of FANC was low as only $21.5 \%$ of health care providers were able to identifying components, majority of the health care providers $72 \%$ were given subsequent antenatal visits based on the traditional ANC. Fifty two percent (52\%) of health workers indicated poor knowledge toward implementation of FANC implementation guidelines. Also $80 \%$ respondents did not discuss birth preparedness, complication readiness as a goal- directed intervention with clients. In up to $92 \%$ of antenatal clinic sessions observed, WHO FANC guidelines was not practiced and the overall knowledge was very low as only $32 \%$ health care providers had knowledge of the concept, and component of FANC. Also Boller, Wyss and Tamer (2009) assessed the quality of ANC in public and private clinics in Dar es salaam and found that guidelines were frequently not followed and diagnostic examination not carried out according to FANC guidelines among $70 \%$ of health care providers in the study area. Majority of the respondents, $82 \%$ during observation of ANC clinic sessions did not practice FANC based on the guidelines. The above finding also agreed with that of Mathole, Lindmark \& Ahlberg (2015). Enhancing FANC in Ghana - An exploration into perception of practicing midwives using an interpretive descriptive design was implemented and the result revealed that majority of the midwives in the study $80 \%$ had good knowledge of FANC and perceived FANC as positive and their practice was highly adequate as $92 \%$ of them were observed to practised it during clinic session. Although the prevailing challenges were many but in the face of these, the midwives in this study were not positive about the delivery of FANC.

\section{MATERIALS AND METHODS}

The quantitative and qualitative designs were adopted for the study. The quantitative design was used to address issues of practice, while the qualitative design was used to address the issues around knowledge of FANC.

The study site was cottage hospital in Okpatu, a rural community in Udi Local government area of Enugu State, South East Nigeria. The cottage hospital provides among others, maternal and child health services and enjoys patronage from communities around it.

The population of the study consisted of 25 health care providers and out of these, only 2 midwives were available throughout the six weeks study period. The permission to carryout the study in the area was obtained from the village head while the administrative permit was obtained from the health committee. Verbal informed consent was obtained from the health care providers that were available during the study.
The instruments for data collection were an indepth interview question guide that sought to determine knowledge and observational checklist that sought to determine practices.

The in-depth interview part of data collection was carried out by two researchers-one asked the questions while the other recorded the responses in writing. This lasted for one and a half hour and was tape recorded. The observation component of data collection took place while the care giver provided antenatal care to pregnant women that accessed the facility. The observation lasted for four weeks and a total of 12 ANC provision was observed.

Descriptive statistics was used to analyze the quantitative data while the data from in-depth interview were transcribed, coded, categorized and subjected to content analysis. Two themes emerged, and these were:

- Poor knowledge of concept of FANC

- Non compliance to the WHO recommendation guidelines of FANC

\section{RESULTS}

\section{Poor knowledge of concepts of FANC}

The results from the study showed inability of the health care providers to define FANC, outline its components and the schedules for the visits. This is evidence in the following excerpts.

"FANC is given to pregnant women from when pregnancy is diagnosed till birth".

"No idea about the components".

"I give them appointments depending of their weeks of gestation."

From her responses it was deduce that she has poor knowledge of concepts, component and timing of visits in FANC

\section{Non Compliance to WHO guidelines for FANC}

Findings from observation and in-depth interview showed non availability of the WHO guideline document in the facility and non compliance to the standard guideline for implementing FANC. Patient visits were not regulated. They were seen any day they showed up and assessment data and treatment provided were documented on the ANC card. This is substantiated by the following excerpts:

"I attend to them whenever I see them".

"I normally take detailed history and register them on the ANC card."

"I paid particular attention to all new clients and those referred by TBAs and probed to know reasons why they left the TBAs".

"I used their ANC card to document their personal information, physical examination and laboratory test". 


\section{DISCUSSION}

The major findings in this study were:

Poor knowledge of concept of FANC and Noncompliance to WHO guidelines for FANC. The healthcare providers demonstrated poor knowledge of concepts, component and timing of visits in FANC. The health worker's current practice does not really comply with the guidelines of the FANC model. Her timing of visits does not correspond with WHO FANC 4 visits, and her estimation for the revisit differs with the FANC manual. The findings showed a major discrepancy between current ANC practice and the requirement of FANC guidelines. The above findings is in line with the findings of Ekabua et al (2011) and Ademola (2011) which showed poor knowledge of the guidelines on knowledge of concepts and schedules of visits for FANC. The study also showed that there was non implementation of FANC guideline causing noncompliance as critical questions were raised about implementation of the FANC guidelines by the health care providers that demonstrated poor knowledge of the concept of FANC. The result was also supported by Rooney (2006) who opined that majority of health workers were still practicing the traditional ANC because of poor knowledge of the concept. The implications of poor knowledge and non implementation of FANC guideline by the health care providers is that it will affect their time for direct contact to share information on pregnancy related issues with their clients. And also the attempt by the government to address the comparatively high maternal and neonatal morbidity and mortality through improved access to quality and evidence based ANC services which will not be realized

\section{CONCLUSION}

The study showed that health care providers in the study have poor knowledge of the concept of FANC and there was non compliance to WHO guideline for FANC.

\section{RECOMMENDATION}

Since FANC contributes to the quality of ANC delivery and subsequent improvement in the health status of pregnant women, it is recommended that seminars and workshop on FANC should be organized for health care providers in cottage hospital Okpatu.

- Improvement of working conditions should focus on the remedy of supply and the strengthening of human resources.

- Retraining, monitoring and supervision on FANC should be carried out for health care providers in the study area.

- There is need for the health care providers to motivate local government authority in the area for supply of more equipment to ensure adequacy of resources to deliver quality care.

- There should be strategies for implementation of existing government policy concerning FANC.

\section{REFERENCES}

Adesokan, F. O., 2011. Reproductive Health for all ages. Nigeria: Bosem Publishers LD 145-158.
Ademola, I., 2011. The evolution of quality of care approach for improving FANC to rural Hospital in Nepal. International Journal of Obst \& Gynee 2006 86:86-87. Retrieved April, 2005 from www.elsevier, com/locate/ijgo.

Akpanah, O., 2011. Epidemiological Research. A practice approach for the focused Ante Natal Care. Professional nursing Journal Vol. 9:1, 96104.

Aluko, I., 2006. Focused Ante natal care in practice, Global Health link 9 (4):10.

Boller, C., Wyss, K and Tamer, M., 2009. Quality and comparison of antenatal care in public and private providers in United Republic of Ranzania Bull World Health Organization 2009, 81:116122 Pub. Med Abstract.

Dunstan, R. W., 2010. The midwives textbook of the principles and practice of machinery London: Adams and Charles Black Ltd.

Ekabua, J., Ekabua, I and Njoku, C., 2011. Framework for making focused antenatal care accessible: A review of the Nigerian setting obstet Gynecol dol: 10:5402/2011/253962.

Etuk, S. I., Itam, H and Asquo, E. E., 2007. Morbidity and mortality in booked women who deliver outside health facilities in Calabar, Nigeria. Actatropica 75, (3): 309 - 313 pus Med.

Gaba, M. A., 2011. Birth preparedness and complication readiness, Maternal and child health programme accessed from http//www.mnhighprego.org.

Global Health Technical Briefs. Focused antenatal care.,

2005. A better, cheaper, faster, evidence-based approach retrieved March 14, 2007 from www.maqueb/org tech briefs 1st b12 antenatal pdf.

Jones, M. D., 2008. Emergency obstetrical care in a time of Adis $\left(1^{\text {st }}\right.$ ed) Lagos Catholic Secretariat of Nigeria

Karin, M. O., 2014. Antenatal care in practice. An exploratory study in antenatal care clinic in Kilomero village South-Eastern Tanzania BMC Pregnancy and Childbirth 11:36 doi 1186/14712393, 11-36

Mathole, T. Lindmark, G and Ahlberg, B. M., 2015. Dilemmas and Paradoxes in providing and changing antenatal Care: a study of nurses and midwives in rural Zimbabwe Health policy and planning 2 20:385-393. Pub. Med Abstract

Ojong, Idang N., Uga Adaora $L$ and Chiotu, Catherine N., 2015. Knowledge and attitude of pregnant women towards focused antenatal care services in University of Calabar Teaching Hospital, Calabar, Cross River State, Nigeria. 
International Journal of Nursing, Midwife and Health Related Cases, 1, (1): 14-23, January 2015, eaj

Reproline., 2015. Focused antenatal care: planning and providing care during pregnancy. A maternal and neonatal health prog. Best practice. Http://www.reprolic.

Rooney, C. I. F., 2006. Antenatal care and maternal health: How effective is it. Geneva Switzerland document WHO/MSN/92A, WHO.

WHO., 2005. Life saving skills for nurses and midwives Abuja, Nigeria. OFID.

WHO., 2006. Antenatal care randomized trial: Manual for implementation of the New Model, retrieved from
WHO., 2010. Participant handbook for Nurses/ Midwives life saving skills training DFID. PATHS Geneva.

World Health Organization., 2007. WHO ANC Randomed Trail: Manual for implementation of the new model Geneva. WHO 2007. 